\title{
Uma transição compartilhada: sobre o acolhimento em saúde mental em um ambulatório do processo transexualizador do SUS*1
}

Clarice Cezar Cabral*2

Nuria Malajovich Muñoz*3

Este artigo aborda o acolhimento em saúde mental a pessoas que estão no processo transexualizador a partir de pesquisa qualitativa e faz uso do método da autoetnografia relacional. Discutimos, a partir das narrativas dos participantes, o processo de chegada ao acolhimento, a complexa transformação do corpo e da identidade de gênero e a função do acolhimento nesse percurso. Destacamos a prática narrativa e o compartilhamento de histórias pessoais como modo de produzir sentidos novos para a experiência singular de transição de gênero, aproveitando as diferenças como uma maneira de buscar uma abertura do olhar

*1 Este trabalho é fruto de dissertação de Mestrado Profissional em Atenção Psicossocial, intitulada Por uma transição compartilhada: narrativas autoetnográficas no encontro da atenção psicossocial com o processo transexualizador, orientada pela profa. dra. Nuria Malajovich Muñoz e defendida na Universidade Federal do Rio de Janeiro UFRJ em 2019.

*2,3 Universidade Federal do Rio de Janeiro - UFRJ (Rio de Janeiro, RJ, Brasil). 
e a possibilidade de coexistência de múltiplas perspectivas. Por fim, salientamos a abordagem psicossocial como estratégia fundamental para a construção de um cuidado compartilhado, integral, horizontal, que favoreça a autonomia dos usuários e atenda suas necessidades.

Palavras-chave: Processo transexualizador, saúde mental, narrativas, acolhimento

O Processo Transexualizador do Sistema Único de Saúde (SUS) consiste num conjunto de ações assistenciais de promoção à saúde de transexuais e travestis que pretendem realizar intervenções corporais visando o trânsito de gênero. Faz parte de uma direção política, implementada pelo Ministério da Saúde, que reconhece a orientação sexual e a identidade de gênero como fatores intrínsecos à saúde e que devem ser acolhidos e acompanhados pelo SUS.

A primeira normatização em relação ao processo transexualizador ocorreu no ano de 2008, pelo Ministério da Saúde através da Portaria $n^{\circ} 1707$ (Portaria $n^{\circ} 1707,2008$ ). A inclusão desses procedimentos nas políticas de atenção à saúde foi impulsionada tanto pela crescente judicialização da demanda de regulamentação da inclusão e financiamento público para realização dos procedimentos médico-cirúrgicos bem como pelo aumento da participação social na formulação desta política junto ao Ministério da Saúde (Lionço, 2009). A definição de normas e protocolos de cuidado pelo SUS permitiu o credenciamento e financiamento de serviços, principalmente hospitais universitários que já realizavam o procedimento médico cirúrgico, e formalizou a necessidade da constituição de uma equipe multidisciplinar para atuar segundo as diretrizes norteadoras do SUS. A inserção da transição de gênero dentro de um "processo transexualizador" traz a perspectiva de integralidade em relação às ações de saúde voltadas a essa população, ampliando o cuidado em saúde para outras ações além do custeio de procedimentos médico-cirúrgicos (Lionço, 2009).

No ano de 2013, uma nova portaria foi publicada pelo Ministério da Saúde que regulamenta o Processo Transexualizador do SUS até os dias de hoje (Portaria $n^{\circ} 2.803,2013$ ). Nessa, destaca-se a 


\section{ARTIGOS}

inclusão das travestis e de homens trans como alvo do cuidado no processo transexualizador, a definição da Atenção Básica como porta de entrada do sistema e os critérios para credenciamento das unidades especializadas (Portaria $\left.\mathrm{n}^{\mathrm{o}} 2.803,2013\right)$.

Enfatizamos aqui dois aspectos em relação à portaria que desejamos comentar. O primeiro diz respeito ao protocolo de cumprir dois anos de acompanhamento ambulatorial, antes do encaminhamento para qualquer procedimento cirúrgico. Tal exigência tem como base a Resolução do Conselho Federal de Medicina $n^{\circ} 1955$ (Resolução $n^{\circ} 1955,2010$ ) que circunscreve os critérios necessários para definir quem é o indivíduo transexual e o que é preciso cumprir para ter acesso à cirurgia de transgenitalização. A resolução parte do pressuposto de que a transexualidade seria um transtorno mental cujo tratamento englobaria a correção do corpo para que este se adequasse ao gênero vivido pela pessoa. Para isso, seriam necessários dois anos de acompanhamento psiquiátrico e/ou psicológico para confirmação desse diagnóstico e encaminhamento para cirurgia. $\mathrm{O}$ segundo aspecto diz respeito à exigência de que haja uma equipe multiprofissional com profissionais de saúde mental nos serviços de assistência do Processo Transexualizador. O debate acerca do papel desses profissionais envolve direções diversas em que a patologização da experiência transexual toma lugar de destaque. Caberia ao profissional de saúde mental da equipe atestar a veracidade ou não daquela experiência? Seria confirmar um "diagnóstico" estanque, imutável, sem margem para arrependimentos ou mudanças? Seria descartar "comorbidades" que excluiriam as pessoas do acesso ao tratamento?

Almeida e Murta (2013) enxergam a multiprofissionalidade como um caminho para a materialização da atenção integral e não restrita a intervenções somáticas. Para os autores, a presença da equipe multiprofissional seria o reconhecimento da complexidade dos efeitos subjetivos e sociais das modificações corporais e da trajetória de vida da população trans antes, durante e após a transição de gênero. Dentre esses efeitos, estaria, por exemplo, a frequente experiência de ruptura de laços familiares e sociais, ocasionando uma fraca rede de apoio emocional e econômica para muitas pessoas.

A situação de extrema vulnerabilidade física, psíquica e social na qual muitas pessoas chegam ao serviço de saúde é preciso ser levada em consideração, de modo que se desenhe um cuidado para além das modificações corporais necessárias e desejadas (Arán \& Murta 2009). Cabe ao serviço participar da construção de uma rede de reconhecimento e inclusão social para essas pessoas. 
O acolhimento em saúde mental pode ser uma ferramenta importante do cuidado prestado nos serviços do processo transexualizador do SUS. Possibilita o diálogo aberto e constante com os usuários, entendendo que a relação entre identidade de gênero e saúde mental precisa ser amplamente discutida, ressaltando a importância da assunção, para cada sujeito, de uma identidade de si onde possa se reconhecer, que lhe permita viver e conquistar autonomia. $\mathrm{O}$ acolhimento em saúde mental é um modo psicossocial de cuidado que pode se colocar como alternativa para a construção de uma atenção não prescritiva, sem pretensões diagnósticas do ponto de vista da transexualidade, mas também uma estratégia potente para a sustentação de um processo de construção, junto às pessoas trans e à sociedade, de um lugar possível para a existência de corpos e subjetividades que fogem do binarismo de gênero.

$\mathrm{O}$ encontro entre profissionais e usuárias/os é o principal recurso na construção do cuidado em saúde mental. Requer escuta ativa e disponibilidade dos profissionais para, junto de quem os procura, construir um projeto terapêutico baseado na responsabilização compartilhada do cuidado, respeitando a autonomia das pessoas (Jorge et al., 2011). Essa direção deve estar presente desde o primeiro contato das pessoas com o serviço. Schmidt 262 e Figueiredo (2009) apresentam a função do acolhimento como um dos eixos centrais da organização dos serviços no que diz respeito ao trabalho clínico. Destacam três dimensões do acolhimento: a postura humanizada ao receber e escutar a demanda de quem chega, construindo uma relação de apoio e interesse mútuo; a dimensão técnica que se refere à utilização do saber profissional para produzir respostas a quem procura atendimento; e a perspectiva da reorientação do serviço que se refere ao projeto organizacional e orienta o processo em equipe.

Organizar o acolhimento de modo a produzir encontros férteis entre usuárias/os e equipe é uma etapa fundamental. Exercer o acolhimento diz respeito a uma postura que atravessa os serviços de saúde e seus atores no cotidiano institucional. Para a população trans, o preconceito e a violação de direitos constituem uma barreira de acesso frequente na maioria dos serviços de saúde. Neste sentido, é preciso que o acolhimento, o respeito e a garantia de direitos operem também da porta do consultório para fora.

A possibilidade de haver um lugar de acolhimento em saúde mental para pessoas em transição de gênero pode ser fundamental para enfrentar os desafios advindos dessa experiência. Para Bento (2008), "a transexualidade é uma experiência identitária que está relacionada à capacidade dos sujeitos construírem novos sentidos para os masculinos e os femininos" (pp. 22-23). 


\section{ARTIGOS}

Muitas vezes a necessidade de aproximação de um ideal de homem ou mulher causa grande sofrimento. Tal experiência pode ser carregada de dor e angústia e de uma grande dificuldade de nomear os conflitos vividos. Bento (2014) é precisa ao colocar que "as idealizações de gênero são lugares inabitáveis, vazios de corpos, plenos de dor e frustrações" (p. 113).

Neste sentido, Almeida e Murta (2013) chamam atenção para a necessidade de considerarmos as singularidades e especificidades de cada caso na elaboração de uma proposta terapêutica, já que nem todas/os que nos procuram desejam e necessitam os mesmos procedimentos de cuidado.

O presente artigo tem por objetivo discutir o acolhimento em saúde mental para pessoas adultas que buscam tratamento hormonal para transição de gênero pelo SUS. As narrativas de pessoas que buscaram atendimento em um ambulatório de transição de gênero são utilizadas para elucidar seus percursos de acolhimento em saúde mental. A autora principal deste trabalho foi também a psicóloga responsável pelo acolhimento em saúde mental do referido ambulatório. A pesquisa foi submetida ao comitê de ética da instituição que foi campo de pesquisa e aprovada com o número 71855317.8.3001.5266 e ao comitê de ética da instituição acadêmica onde se deu o mestrado profissional e aprovada com o número 71855317.8.0000.5263. Todos os sujeitos aceitaram participar da presente investigação, escolheram seus pseudônimos e assinaram Termo de Consentimento Livre e Esclarecido.

\section{Método}

A presente investigação utiliza metodologia de pesquisa inspirada na autoetnografia relacional. Esse método tem como processo e produto de pesquisa a construção de narrativas escritas em colaboração entre a autora principal e as/os participantes da pesquisa. Nosso interesse pelo método se justifica por sua confluência com o modo de operar no campo da saúde mental, principalmente no dispositivo de acolhimento, possibilitando uma forma de compreender a experiência que se constrói na interação entre sujeitos, no caso, pesquisadora e participantes, em determinado tempo e contexto. A abordagem narrativa permite acessar a experiência subjetiva de pessoas que estão em processo de transição de gênero e possibilita, no movimento inverso, a autorreflexão por parte da autora principal enquanto psicóloga que atua no dispositivo de acolhimento em saúde mental para 
pessoas em processo transexualizador. A dupla função de pesquisadora e psicóloga responsável pelo acolhimento em saúde mental insere-se em uma proposta de pesquisa que traz uma participação ativa e sem pretensões de neutralidade. A autoetnografia é um método que proporciona um modo de investigação que parte da produção de um encontro entre pesquisadora e participante, dando destaque ao plano relacional e autorreflexivo.

A autoetnografia relacional é uma abordagem qualitativa de pesquisa utilizada em situações que visam à construção de relatos de experiência de vida de uma/um participante, a partir da construção de narrativas obtidas em conversas com a/o pesquisadora/or. Contador e o ouvinte da história participam, na medida do possível, da construção da experiência e de seu significado (Adams, Jones \& Ellis, 2015). Ellis e Rawicki (2013) destacam que a autoetnografia relacional permite que o pesquisador se aprofunde na experiência do outro e, ao mesmo tempo, reflita sobre sua experiência, efetuando um percurso de ir e vir entre participante e pesquisador e participante e contexto.

Esse método permite que o pesquisador reflita sobre sua experiência ao mesmo tempo em que recolhe a história trazida pelo participante e, por essa razão, aplica-se a esta situação de pesquisa na qual a autora principal tem um envolvimento com as/os participantes - neste caso, profissional. Desta forma, o processo de investigação se entrelaça ao processo de construção e transformação da experiência dos sujeitos envolvidos (pesquisadora e participantes).

Os laços interpessoais entre pesquisadores e participantes se constituem como uma dimensão importante da investigação, sendo recomendado que o pesquisador consulte os participantes sobre o produto da pesquisa, "permitindo que possam dar respostas, e/ou reconhecer como se sentem acerca do que se escreve sobre eles e sobre a forma como foram representados no texto" (Ellis, Adams \& Bochner, 2015, p. 261).

Realizamos entrevistas não estruturadas que foram áudio-gravadas, transcritas e depois reescritas junto às/aos participantes da pesquisa, servindo de base para os textos finais.

As narrativas escritas foram construídas ao longo de três encontros subsequentes com cada participante da pesquisa. No primeiro encontro, a entrevista foi áudio-gravada e as/os entrevistadas/os foram convidadas/os a dar o seu depoimento pessoal sobre o seguinte: acerca de sua história de desconforto com o gênero atribuído ao nascer; sobre a decisão em iniciar a transição de gênero; e sobre sua experiência no percurso de acolhimento em saúde mental realizado no ambulatório. A conversa foi transcrita e organizada 
pela pesquisadora em um texto escrito que, em um segundo tempo, foi reapresentado às/aos entrevistadas/os. Essa primeira versão do texto escrito incluiu a narrativa das/dos participantes e algumas reflexões da pesquisadora a partir da conversa e das percepções ao longo do acompanhamento. Foi estabelecido um diálogo com o texto, apresentando algumas considerações, dúvidas e pontos de vista pessoais obtidos nesse processo de escuta e escrita das histórias, a partir do qual também foi realizada uma autorreflexão. No segundo encontro, houve uma conversa entre a autora principal e as/os participantes no sentido de modificar o conteúdo do texto de forma que estas/estes se sentissem representadas/os, reescrevendo e aprofundando questões que julgassem pertinentes. Esse encontro foi áudio-gravado apenas com o objetivo de auxiliar a escrita do texto final, que foi validado no terceiro e último encontro.

No presente artigo, apresentamos recortes narrativos sobre o processo de acolhimento de três participantes que foram categorizados nos seguintes eixos temáticos: a chegada ao acolhimento, o percurso complexo de transformação e a função do acolhimento. As participantes Daniellie e Alessandra são mulheres trans acompanhadas individualmente de maneira regular ao longo de dois anos e Martim é um homem trans, recém-ingressado no dispositivo de acolhimento do ambulatório. Daniellie e Alessandra são brancas, oriundas da classe média, tiveram moradia própria e nível superior. Martim é negro, de classe popular, sem acesso a nível superior e a emprego formal. O convite às/aos participantes levou em consideração a relação estabelecida com a autora principal ao longo do acompanhamento no ambulatório, as histórias e trajetórias de transição, o interesse em relatar suas histórias e/ou refletir sobre a experiência vivenciada. Ou seja, o desejo de falar de si e ser ouvida/o. Todas as decisões sobre o que e como contar foram tomadas em conjunto com as/os participantes, bem como a escolha do nome usado nas narrativas.

A partir deste ponto utilizaremos a primeira pessoa quando a passagem em questão abordar as reflexões da autora principal em seu processo de investigação.

\section{Resultados e Discussão}

\section{A chegada ao acolhimento}

A transição de gênero é um processo amplo, que engloba percursos e interações que extrapolam a utilização de instrumentos biomédicos (Arán, 2019). 
Muitas vezes se inicia antes da chegada ao serviço de saúde, a partir do uso de tecnologias mais leves como corte de cabelo, troca de vestuário, nomeação etc. e se configura como um movimento que antecede e sucede as instituições de saúde, sendo estas lugares de passagem. Proporcionar uma atenção integral a quem nos procura e acessar a diversidade de motivos que levam as pessoas a tomar a decisão por ingressar numa "transição acompanhada" são fundamentais para conhecer percursos, experiências e vivências absolutamente singulares na construção de uma identidade de gênero.

Daniellie chegou ao acolhimento quando estava se estabelecendo no Rio de Janeiro, depois de um período que passou morando no exterior. Tinha emprego estável, não aparentava estar em sofrimento psíquico e nem demandava acompanhamento intensivo. Em uma ocasião, quando ainda morava no exterior, Daniellie experimentou, por sugestão de alguns amigos, vestir-se de mulher. Gostou muito do resultado e passou a vestir-se com frequência com roupas femininas. Voltando ao Brasil, sentiu-se confusa, não sabia como ou o que fazer com essa experiência que a havia marcado tão profundamente.

Quando eu vim para cá eu não tinha nada planejado. Só estava 266 querendo entender o que estava acontecendo comigo. Até hoje eu não consigo entender ou explicar o porquê de um homem se vestir de mulher. Eu tenho esse desejo e não consigo entendê-lo. (Daniellie)

Já Alessandra veio ao acolhimento em profundo sofrimento e em situação de extrema vulnerabilidade. Era tomada por uma intensa dificuldade de nomear o que sentia. Vinha sofrendo de crises de pânico, com algumas tentativas de suicídio prévias, apresentava-se chorosa, relatava inúmeras brigas com a mãe nas quais tinha reações desesperadas. Ela havia voltado a morar com a mãe, que não aceitava de forma alguma o que ela afirmava ser. Estava divorciada, afastada do filho e sem emprego. A decisão da transição foi uma surpresa para sua família, um desvio de rota, da ordem da loucura. Tudo era intenso, forte e urgente. Sua história se revelou em fragmentos, que foram sendo costurados em encontros semanais.

Às vezes ainda me sinto muito perto do início da transição para ter um olhar mais crítico. Ainda estou nessa de me colocar no mundo, de saber como me posicionar, de como conseguir emprego, de como me relacionar, de como reagir ao mundo. (Alessandra)

A chegada ao acolhimento também não foi fácil para Martim. Tímido, cabisbaixo, tinha muita dificuldade em falar de si. Precisou de um tempo para 
dizer o quanto estar em um serviço de saúde era delicado para ele, pois havia enfrentado uma dura negativa por parte da primeira profissional de saúde que o havia recebido anteriormente. Talvez, por ser um ambulatório especializado, ele se sentisse um pouco mais protegido. Havia empreendido um caminho pregresso trabalhoso que envolveu a passagem pela atenção básica e o contato com vários profissionais. A cada vez se expor, explicar quem se é, o que se quer, aguardar a vaga, passar pela triagem do hospital. Contar novamente sua história. Não é uma tarefa fácil.

Não sabia que existia esse tipo de acompanhamento. Meu amigo falou que passou por muita coisa antes de conseguir, e eu fiquei com receio de passar por isso também. Então decidi procurar uma clínica particular, mas a médica falou que não poderia me dar o pedido para tratamento porque ela era cristã. Como eu não queria passar por esse tipo de constrangimento, eu comecei a fazer a aplicação de hormônio por conta própria até aceitar que precisava de acompanhamento. (Martim)

Tomando o desencontro narrado por Martim com a primeira profissional de saúde, percebemos que esse tipo de barreira ocorre de forma frequente. Ainda que suponhamos que a principal causa seja o preconceito e o estigma dos profissionais em relação aos corpos não normativos, é preciso questionar qual função o atendimento especializado ocupa na política de saúde voltada à população trans. Oliveira e Romanini (2020) comentam que é fundamental o encontro entre o profissional de saúde e usuário para que o trabalho em saúde aconteça. Para os autores, o acesso da população trans aos serviços da atenção básica se dá, em grande parte das vezes, para conseguir um encaminhamento para serviços especializados. Tal situação dificulta a vinculação desses usuários com a equipe do território de referência e faz com que, muitas vezes, as pessoas trans sintam-se mais seguras em serviços especializados que têm profissionais mais bem preparados para acolher suas demandas específicas. Ou seja, mostram ser fundamental o estabelecimento de relação entre a atenção básica e especializada na oferta de um cuidado integral à saúde dessa população.

Em nosso Estado, a relação entre os serviços costuma se encerrar no encaminhamento. Não contamos ainda com nenhuma política de articulação ou de compartilhamento do cuidado. Existem iniciativas a respeito e ações em algumas unidades de saúde para acolhimento de pessoas LGBTQI+ e acompanhamento de pessoas trans, mas seria necessário organizar o trabalho em uma rede que funcione de forma ativa e ordenada. Nem todas as situações 
necessitam de um especialista, a discussão sobre saúde da população trans precisa ser levada para atenção básica na construção de um caminho mais inclusivo.

Do lado dos centros especializados, o risco é a reprodução de um modelo ambulatorial clássico em saúde mental, que já sofreu diversas críticas no sentido de desconsiderar o conceito ampliado de saúde e produzir um cuidado isolado e pouco articulado com a rede de atenção à saúde e intersetorial. Passar do modelo biomédico e de atendimentos psicoterápicos individuais para o modelo do acolhimento em saúde mental é um desafio que se coloca também para os ambulatórios da rede de saúde mental. A existência de equipe multiprofissional é uma possibilidade, mas não uma garantia de que o trabalho ocorra de forma integral, horizontal e buscando a autonomia das/dos usuárias/os. É possível que continue a operar de forma compartimentalizada e hierárquica, em que dificilmente há uma abertura para imprimir a lógica da atenção psicossocial.

Ferreira et al. (2017) apontam que o preconceito e a falta de preparo dos profissionais de saúde para lidarem com questões de gênero dificultam o acesso e a permanência das pessoas trans nos serviços, afastando-as do cuidado em saúde. Os autores reforçam a necessidade de treinamento e capacitação dos profissionais para que sejam capazes de ouvir e perceber as demandas latentes das pessoas trans e assim poderem propor uma reorganização dos serviços que contemple as necessidades e especificidades dessas pessoas.

\section{O complexo percurso de transformação}

A transição envolve um percurso complexo de transformação que compreende um trabalho de revisão e ressignificação do passado, localizando vestígios que possam garantir um sentido de permanência, de continuidade existencial. Memórias e experiências individuais se articulam com produções da cultura na sustentação de um percurso ao mesmo tempo novo e conhecido, ou melhor, reconhecido.

Foi na função de espectadora e ouvinte que acolhi Daniellie quando veio ao ambulatório compartilhar sua história e apresentar seus planos de transição. Apesar de eu não ter sentido à época que havia muita entrada para interferir no que se passava com ela, me surpreendi quando, na entrevista de pesquisa, ela disse que foi fundamental poder contar a sua história para alguém e poder assim tornar-se ouvinte de si mesma. 


\section{ARTIGOS}

A palavra-chave seria internalização. Foi muito bom abordar a questão primando por uma condição existencial e não por um bate-papo informal. As perguntas ajudaram-me a responder questões sobre o que estava acontecendo comigo. E ouvir a sua própria voz falando sobre esses assuntos promove uma internalização mais efetiva dos vários assuntos. Será que eu estou aqui em erro? Será que eu estou aqui da forma correta? O fato de ser bem acolhido ${ }^{1}$ e aceito facilitou a decisão da transição. Eu sempre tratei os nossos encontros como uma possibilidade de falar mais sobre o assunto. Eu não tinha com quem falar. (Daniellie)

Para Alessandra, a decisão da transição veio após uma vivência traumática que reavivou dores há muito adormecidas e exigiu uma reescrita de si. O acolhimento teve como função ajudá-la a se ressituar em suas relações familiares, amores, casamento, paternidade. Um trabalho de reconstrução que envolveu um processo complexo de desligamento de uma identidade masculina com a qual construiu parte importante de sua história.

No início, usei esse espaço principalmente para chorar. Eu vinha para o ambulatório, eu falava, chorava. Saía daqui, ia para casa e continuava chorando. No início, era uma catarse. Um lugar onde eu precisava falar e chorar com uma pessoa que sei que não vai me julgar, que não vai dar opinião descontextualizada, que não vai emitir preconceito de forma alguma, e que vai me acolher. E ai eu tentei começar a me organizar. Mas ainda há muitas questões pertinentes às violências que sofri durante a infância e a adolescência. (Alessandra)

Martim demonstrou muito interesse em contar a sua história a alguém que pudesse ouvi-lo e ajudá-lo a experimentar outras perspectivas. A observação do mundo, o interesse por histórias e a reflexão sobre si foram, desde muito cedo, recursos que encontrou para se relacionar com aquilo que não podia dividir com ninguém.

Desde criança eu já me sentia diferente. Diferente das minhas duas irmãs e totalmente fora do enquadre familiar. Como o local em que eu morava era muito precário de informações, eu ficava distante de muitas atualizações. Havia coisas que não deveriam ser conversadas, não poderiam

${ }^{1} \mathrm{O}$ uso gênero masculino foi uma escolha da participante. A mesma referiu-se a si desta forma no momento da entrevista e optou por não alterar o texto. 
ser faladas. Não tinha como saber, como conversar. Sentia que eu realmente era diferente, dentro de mim. (Martim)

As/Os participantes situam a importância de encontrar alguém que possa se fazer destinatário de suas inquietações, acompanhando o complexo percurso de reescrita de si. É interessante notar que cada uma/um precisou se reinventar a seu modo buscando algum tipo de esteio, segurança e estabilidade ao assumir uma identidade não inteiramente nova, mas que se organiza de forma inédita no caso de Daniellie, que emerge como salvação no caso de Alessandra e como afirmação para Martim.

Para Louro (2001), reconhecer-se numa identidade é uma questão pessoal e política e a comunidade funcionaria como lugar de acolhida e suporte, uma espécie de lar. A comunidade LGBTQI+ no exterior, para Daniellie, a militância política para Alessandra, a relação com alguns amigos, para Martim, foram importantes redes afetivas de apoio durante o processo.

O acolhimento em saúde mental se constituiu como mais um laço nessa rede, propiciando uma transição compartilhada e que não se esgota no corpo ou em uma posição identitária. A prática narrativa pode auxiliar a alinhavar as diferentes dimensões envolvidas no processo de construção de identidade. Mas, como mostra Serpa Jr. (2011) recorrendo a Ricoeur, a narrativa não se dá sem o corpo: "a corporificação estrutura a experiência e a cognição enquanto uma perspectiva interna contínua no tempo, servindo como fundamento para a produção da narrativa" (p. 4681). A narrativa é a forma privilegiada pela qual "organizamos nossa experiência e nossa memória de acontecimentos humanos" (Bruner, 1991 p. 4), sendo por isso um meio profícuo de acessar a forma como o sujeito vivencia sua experiência (Leal \& Serpa Jr., 2013).

A intertextualidade parece ter papel central na amarração desses elementos, como via de compartilhamento de narrativas e construção de si. $\mathrm{O}$ dispositivo de acolhimento contribuiu para encontrar a liga entre os ingredientes, para que cada uma/um pudesse acolher aquilo que lhe era próprio na pluralidade de possibilidades das identificações. Neste sentido, podemos questionar se há um início ou um fim para a transição, na medida em que somos constantemente atravessados por contingências que exigem assimilação e narrativas que as envelopem, de modo a encontrar morada para as experiências vividas. 


\section{ARTIGOS}

\section{Compartilhando a transição}

Daniellie recusa modelos prontos, designações dadas. Aprendi com ela a ficar mais confortável diante disso, pois quem deve decidir de que forma transitar, qual a melhor maneira de vivenciar o seu gênero, são os próprios sujeitos. De alguma forma, somos capturados por uma necessidade de fazer leituras nos utilizando de padrões disponíveis. Daniellie conserva diferentes visões acerca das determinações de sua experiência pessoal. Para ela não é claro se teria uma pré-disposição à transexualidade ou se a transição teria sido escolha ou influência das interações que estabeleceu no exterior. Por conta disso, fui incialmente cautelosa em relação à sua decisão de iniciar o processo transexualizador; parecia ser conveniente para ela poder apresentar-se em sua versão masculina quando lhe conviesse. Eu me perguntava se a transição não seria uma ação precoce, algo que limitaria certo trânsito que, a meu ver, tinha uma função para ela. No entanto, Daniellie sempre se colocou com muita segurança em relação a essa escolha. A cirurgia dos seios e da face foi o momento que marcou uma virada importante da transição.

Comecei a planejar uma transição gradual. Preparei-me para cirurgia do rosto e dos seios um ano antes de realizá-las. O processo de internalização seguiu. Comecei a organizar o guarda-roupa, comecei a ver uma vida meio diferenciada do que eu tinha e, aconteceu. Chega o dia da cirurgia, você deita, dorme, acorda totalmente diferente e aquilo ali passa a ser o novo eu. Então, continuei vindo aqui e todos os meus outros medos/receios e fui resolvendo as questões nas nossas conversas. Resquicios de coisas boas e ruins foram processados, ou convertidos ou simplesmente abandonados. Penso que o resultado, por enquanto, está indo bem. (Daniellie)

Já Alessandra pôde, através das palavras, encontrar contornos para o seu sofrimento, desviando-se do abismo e constituindo uma teia a partir de fios soltos que lhe permitiram costurar sua história. Junto a ela, fizemos composições, rearranjando novos e antigos retalhos. Por vezes, não foi fácil acompanhá-la nas narrativas que davam suporte à sua construção, sendo desafiador libertar-se de uma representação da transexualidade que circulava nos trabalhos acadêmicos, nos discursos políticos e biomédicos. Era preciso que eu fizesse um exercício constante de singularizá-la, sem perder de vista o contexto.

Eu sei também que você passa por um processo de construção junto comigo. Junto com as pacientes, você também está aprendendo, você também 
está ouvindo, você também está crescendo. Também está num processo de transformação, não é uma coisa de via única. É uma troca, uma via de mão dupla. Vejo isso como um processo pedagógico, meu e seu, onde você aprende comigo e eu aprendo com você, onde a gente vai se desconstruindo da nossa realidade, E tiveram alguns rastros ideológicos. Por exemplo, a questão da construção social, que eu tive que falar: "Não é isso, Clarice. É outra coisa". Eu tive que colocar o meu local de fala, que você, por ser cisgênera, não possui. Mas é normal. Eu tenho que fazer isso com o mundo inteiro: impor um local de fala, de forma didática ou agressiva, mas tenho que impor o meu local de fala às pessoas. É normal. (Alessandra)

As escolhas de Martim implicaram complexas negociações com as exigências e expectativas das pessoas de seu entorno. Entre cobranças sociais, religiosas e familiares, espaços de resistência lhe permitiram encontrar elementos que o ajudaram a construir sua identidade. Algumas amizades, a presença de sua companheira, de sua mãe e, agora, do serviço de saúde constituíram-se como importantes elementos de sua rede que, junto à espiritualidade e à literatura the forneceram referências para a construção de si. Percebi 272 que alguns recursos precisavam ser valorizados, como a leitura e a escrita, ajudando a dar sentido à sua vida e à sua história.

Acho importante você se conhecer. São oportunidades de falar coisas que você não tem coragem de falar para quem está do seu lado. Tenho dificuldade em falar sobre a minha vida. Tem muitas questões que não falei, que não tenho coragem de conversar. O acompanhamento é importante, você vai se sentindo mais à vontade aos poucos. (Martim)

O acolhimento em saúde mental, para além do pacote hormônio-psicologia-psiquiatria, serviu para Martim como ponto de partida para produzir conexões com lugares e pessoas e possibilitar que ele pudesse continuar o seu caminho. Transitar tem envolvido um intenso trabalho de localização de elementos a serem preservados em sua história e de criação de referências novas e singulares. Um processo complexo, preservar a tradição e a religião com a qual foi criado, manter seu lugar na família e junto a isso se conhecer melhor, encontrar seu lugar no mundo.

Nem sempre uma pessoa que procura ajuda em saúde mental o faz porque acha que tem algum transtorno, mas sim, porque sente algum mal-estar na relação consigo e com o mundo. Considerar que sofrimento psíquico é algo que pode ser experimentado por qualquer pessoa em 
qualquer momento da vida, sendo importante compreender de que forma ela se relaciona com o seu sofrimento e, acima de tudo, que se sintam acolhidas e respeitadas (Leal \& Muñoz, 2014). É preciso acolher esse mal-estar ao invés de tentar encaixá-lo em categorias diagnósticas e protocolos terapêuticos.

Como mostra Arán (2019), é preciso adotar uma noção mais ampla de saúde capaz de englobar a diversidade sexual e uma perspectiva clínica que permita o acolhimento da experiência trans deixando de lado concepções normativas do desejo e dos processos de identificação. É fundamental, para isso, a valorização da experiência e do saber de quem nos procura e acreditar em sua capacidade de gerenciar a própria vida e de fazer escolhas, de modo a estar atento aos recursos utilizados por cada pessoa para lidar com seu sofrimento.

\section{Considerações finais}

A relação entre identidade de gênero e saúde mental precisa ser amplamente discutida, ressaltando a importância de assunção para cada sujeito de uma identidade de si onde se reconheça, possa viver e conquistar autonomia.

Como escutar sem falar em nome do outro, sem silenciar sua voz? O percurso de investigação nos mostrou que a construção de narrativas pode ser um instrumento interessante para o trabalho no acolhimento em saúde mental. Segundo Ellis, Adams \& Bochner (2015), escrever histórias pessoais também pode ser terapêutico para os autores. Isto porque escrevemos para dar sentido a nós mesmos e às nossas experiências, além de possibilitar o questionamento de histórias convencionais e normativas que projetam sobre nós como devemos nos comportar ou agir. Escrever histórias pessoais de forma colaborativa pode ajudar a produzir sentidos novos para as experiências, aproveitando as diferenças como uma maneira de buscar uma abertura do olhar e a possibilidade de coexistência de múltiplas perspectivas.

$\mathrm{O}$ desenho de um modo de cuidado para pessoas em processo de transição de gênero deve incluir o sujeito e sua vivência, aproximando o serviço de saúde da vida e dos dilemas cotidianos que se apresentam na experiência de transição para cada uma/um que nos procura. Para isso, é necessário sustentar um lugar de produção de narrativas singulares que podem se aproximar ou não daquelas produzidas pelos discursos oficiais e manuais diagnósticos, mas que costurem um projeto existencial possível. 
Para Borba (2014) esta seria uma forma de interagir com a classificação e abalá-la, mostrando que "(...) a transexualidade não passa de uma experiência identitária (como todas as outras) múltipla e fragmentada, produzida local e cumulativamente" (p. 92). Possibilitar interações nos serviços do processo transexualizador torna-se assim um grande desafio de modo a tornar possível o aparecimento de narrativas alternativas.

Convidar as pessoas a uma posição de protagonista em seu percurso de cuidado em saúde é fundamental, permitindo a inclusão de fatores que não podem ser negligenciados. Ao invés de a pergunta girar em torno de saber se aquela pessoa diante de nós é trans ou não, precisamos ouvir o que a levou a estar ali, diante de nós, num determinado momento da vida, que pedido ela nos faz e como ela lida com as soluções que encontrou para estar na vida. Além disso, quais os recursos que ela têm para lidar com seu sofrimento ou com as violências que a atingem, que suporte ela encontra em seu meio, quais são seus planos.

Neste sentido, clínica e política se articulam ao se basearem no direito ao cuidado na comunidade e na necessidade de uma intervenção na cultura que inclua a possibilidade e a legitimidade da existência de subjetividades fora do padrão. A sustentação de um acolhimento eticamente engajado e ampliado passa pela valorização de formas singulares dos sujeitos se relacionarem consigo e com o mundo, bem como inclui formas de intervenção na cultura para permitir um lugar social mais inclusivo.

Muitas vezes sentimentos de estranheza em relação ao corpo e ao gênero são precedidos por períodos de intenso sofrimento que ainda não consegue ser nomeado. Algumas pessoas experimentam a sensação de ainda não saber o que está acontecendo, acompanhado de angústia, isolamento, ideações e/ou tentativas de suicídio. Chegar a um atendimento especializado costuma ocorrer depois de passadas algumas decisões e rupturas.

Neste sentido, a função do acolhimento é fundamental. Um acolhimento que seja capaz de aceitar incondicionalmente quem chega até o serviço e que esteja interessado em ouvir a história das pessoas sem tentar encaixá-las em protocolos de tratamento. Procurar entender qual relação estabelece consigo e com o mundo e que estratégias utilizou para lidar com seus momentos de angústia e sofrimento é necessário para que se coloque o indivíduo numa posição de protagonista e capaz de desenvolver recursos de produção de sua identidade.

Os primeiros contatos precisam ir além das questões de gênero para que apareçam outros aspectos da vida dos indivíduos. É comum as 


\section{ARTIGOS}

pessoas chegarem contando suas histórias de forma protocolar, coladas em determinada posição e excluindo aspectos, passagens e até mesmo imagens, que ela repele. A ruptura do passado com o tempo presente, com a vida vivida em outro gênero, com amigos, família, precisa encontrar um espaço para ser descrita, narrada, costurada.

Tal movimento pode ocorrer de diversas formas, não apenas num modelo de psicoterapia individual. Encontros pontuais, intervenções em momentos de crise, participação em grupos ou mesmo uma oferta de escuta futura para quem ainda não se sente à vontade para conversar podem trazer efeitos importantes. $\mathrm{O}$ acolhimento pode se dar em diversas configurações, a forma como vai acontecer deve ser sempre negociada com os sujeitos e revista a qualquer momento.

Além disso, é preciso considerar que as pessoas estão na vida, circulando, pertencendo e interagindo com diversas redes onde ocorrem trocas de experiências. $\mathrm{O}$ suporte à transição muitas vezes não é encontrado apenas nas relações estabelecidas no serviço de saúde, mas em outras formas coletivas de sustentação que auxiliam o indivíduo a se localizar no mundo e em relação a si mesmo. Quando estas redes existem e são utilizadas de forma ativa e afetiva pelas pessoas em transição, podem produzir efeitos apaziguadores no sofrimento e abrir novas possibilidades de existência. $\mathrm{O}$ acompanhamento em saúde mental precisa levar isso em consideração e estimular ações coletivas neste sentido em que um possa se enriquecer com a experiência do outro.

Existe um hiato entre a experiência de transição vivida pelas pessoas que nos procuram e a forma como conseguimos compreendê-la e pensá-la. As narrativas dão acesso a outro ponto de vista sobre o vivido subjetivo no processo de transição de gênero. O esforço de fazer circular as narrativas produzidas nos espaços de acolhimento pode ser um caminho para produzir fissuras nos conhecimentos estabelecidos e ampliar o repertório narrativo de profissionais envolvidos no cuidado. Ao ocuparmos um lugar de escuta, colocando entre parênteses os protocolos e os saberes instituídos, abre-se um espaço para a circulação de diferentes perspectivas e compartilhamentos de experiências.

\section{Referências}

Adams, T., Jones, S., \& Ellis, C. (2015). Autoethnography. Understanding qualitative research. Oxford University Press. 
Almeida, G., \& Murta, D. (2013). Reflexões sobre a possibilidade da despatologização da transexualidade e a necessidade da assistência integral à saúde de transexuais no Brasil. Sexualidad, Salud y Sociedad, 14, 380-407. https://doi.org/10.1590/S1984-64872013000200017.

Arán, M. (2019). A psicoterapia no processo transexualizador do SUS: por uma nova cartografia da diversidade sexual. In A. N. França (Org.), Psicologia \& diversidade sexual: assim se passaram vinte anos (pp. 19-36). Conselho Regional de Psicologia do Rio de Janeiro. Recuperado de: <http://www.crprj.org.br/site/ wp-content/uploads/2019/09/diversidade_web.pdf $>$.

Arán, M., \& Murta, D. (2009). Do diagnóstico de transtorno de identidade de gênero às redescrições da experiência da transexualidade: uma reflexão sobre gênero, tecnologia e saúde. Physis: Revista de Saúde Coletiva, 19(1), 15-41. https://doi. org/10.1590/S0103-73312009000100003.

Bento, B. A. M. (2008). O que é transexualidade?. São Paulo, SP: Brasiliense.

Bento, B. A. M. (2014). A Reinvenção do Corpo: sexualidade e gênero na experiência transexual. ( $2^{\mathrm{a}}$ ed.). Natal: EDUFRN.

Borba, R. (2014). Sobre os obstáculos discursivos para a atenção integral e humanizada à saúde de pessoas transexuais. Sexualidad, Salud y Sociedad, 17, 66-97. Epub May 00, 2014. https://doi.org/10.1590/1984-6487.sess.2014.17.06.a.

Bruner, J. (1991). A construção narrativa da realidade. Critical Inquiry, 18(1), 1-21.

Ellis, C., Adams, T. E., \& Bochner, A. P. (2015). Autoetnografía: un panorama. Astrolabio, 14, 249-273. Recuperado de: <https://revistas.unc.edu.ar/index.php/ astrolabio/article/view/11626>.

Ellis, C., \& Rawicki, J. (2013). Collaborative Witnessing of Survival During the Holocaust: An Exemplar of Relational Autoethnography. Qualitative Inquiry, 19(5), 366-380. https://doi.org/10.1177/1077800413479562.

Ferreira, B. O., Nascimento, E. F., Pedrosa, J. I. S., \& Monte, L. M. I. do (2017). Vivências de travestis no acesso ao SUS. Physis: Revista de Saúde Coletiva, 27(4), 1023-1038. https://doi.org/10.1590/s0103-73312017000400009.

Jorge, M. S. B., Pinto, D. M., Quinderé, P. H. D., Pinto, A. G. A., Sousa, F. S. P. de, \& Cavalcante, C. M. (2011). Promoção da Saúde Mental - Tecnologias do Cuidado: vínculo, acolhimento, co-responsabilização e autonomia. Ciência \& Saúde Coletiva, 16(7), 3051-3060. https://doi.org/10.1590/S1413-81232011000800005.

Leal, E. M., \& Muñoz, N. M. (2014). Estratégias de intervenção em saúde mental. In M. A. S. Jorge, M. C. A. Carvalho, P. R. F. Silva da (Orgs.), Políticas e cuidado em saúde mental: contribuições para a prática profissional (pp. 75-97). Rio de Janeiro, RJ: Editora Fiocruz.

Leal, E. M., \& Serpa Junior, O. D. de. (2013). Acesso à experiência em primeira 


\section{ARTIGOS}

pessoa na pesquisa em Saúde Mental. Ciência \& Saúde Coletiva, 18(10), 2939-2948. https://doi.org/10.1590/S1413-81232013001000018.

Lionço, T. (2009). Atenção integral à saúde e diversidade sexual no Processo Transexualizador do SUS: avanços, impasses, desafios. Physis: Revista de Saúde Coletiva, 19(1), 43-63. https://doi.org/10.1590/S0103-73312009000100004.

Louro, G. L. (2001). Teoria queer: uma política pós-identitária para a educação. Revista Estudos Feministas, 9(2), 541-553. https://doi.org/10.1590/S0104$026 X 2001000200012$.

Oliveira, I. de, \& Romanini, M. (2020). (Re)escrevendo roteiros (in)visíveis: a trajetória de mulheres transgênero nas políticas públicas de saúde. Saúde e Sociedade, 29(1), e170961. Epub 03 de feveiro de 2020. https://doi.org/10.1590/ s0104-12902020170961.

Portaria $\mathrm{n}^{\mathrm{o}} 1.707$ (2008, 18 de agosto). Institui, no âmbito do Sistema Único de Saúde (SUS), o Processo Transexualizador, a ser implantado nas unidades federadas, respeitadas as competências das três esferas de gestão. Revogada pela portaria $n^{\circ}$ 2.803/13. Diário Oficial da União. Brasilia - DF. Recuperada de: <http://bvsms. saude.gov.br/bvs/saudelegis/gm/2008/prt1707_18_08_2008.html >.

Portaria $n^{\circ} 2.803$ (2013, 19 de novembro). Redefine e amplia o processo transexualizador no Sistema Único de Saúde (SUS). Diário Oficial da União. Brasília, DF. Recuperada de: <http://bvsms.saude.gov.br/bvs/saudelegis/gm/2013/ prt2803_19_11_2013.html>.

Resolução $n^{\circ} 1.482$ (1997, 19 de setembro). Autoriza a título experimental, a realização de cirurgia de transgenitalização do tipo neocolpovulvoplastia, neofaloplastia e ou procedimentos complementares sobre gônadas e caracteres sexuais secundários com o tratamento dos casos de transexualismo. Revogada pela Resolução n ${ }^{\circ}$ 1652/2002. Conselho Federal de Medicina. Diário Oficial da União. Poder Executivo, Brasília, DF. Recuperada de: <https://sistemas.cfm.org. br/normas/arquivos/resolucoes/BR/1997/1482_1997.pdf >.

Resolução $\mathrm{n}^{\mathrm{o}} 1.955$ (2010,3 de setembro). Dispõe sobre a cirurgia de transgenitalismo e revoga a Resolução $n^{\circ} 1.652 / 02$. Revogada pela Resolução $n^{o}$ 2.265/2019. Conselho Federal de Medicina. Diário Oficial da União. Poder Executivo, Brasília, DF. Recuperada de: <https://sistemas.cfm.org.br/normas/ arquivos/resolucoes/BR/2010/1955_2010.pdf $>$.

Schmidt, M. B., \& Figueiredo, A. C. (2009). Acesso, acolhimento e acompanhamento: três desafios para o cotidiano da clínica em saúde mental. Revista Latinoamericana de Psicopatologia Fundamental, 12(1), 130-140. https://doi. org/10.1590/S1415-47142009000100009.

Serpa Junior, O. D. de (2011). O papel da psiquiatria na reforma psiquiátrica. Ciência \& Saúde Coletiva, 16(12), 4675-4684. https://dx.doi.org/10.1590/S141381232011001300016. 


\section{Resumos}

(A shared transition: on mental health care in an outpatient clinic aimed at the transsexualizing process of the Brazilian Integrated Health System)

This article addresses the reception in mental health of people undergoing transsexualization; it is based on a qualitative research that was conducted by using the relational autoethnography method. The narratives of the participants are analyzed to discuss the process of arriving at the reception, the complex physical transformation of both body and gender identity, and the function of the reception in that process. We highlight the narrative practice and the sharing of personal stories as a way of producing new meanings for the unique experience of gender transition, taking advantage of differences as a way of seeking a broader vision and the possibility of coexistence of multiple perspectives. To conclude, we emphasize the psychosocial approach as a fundamental strategy for building shared, comprehensive, horizontal care that favors users' autonomy and meets their needs.

Key words: Transsexualizing process, mental health, narratives, reception

(Une transition partagée: à propos de l'accueil en santé mentale d'une clinique externe pour le processus de transsexualisation du système de santé publique brésilien)

Cet article analyse l'accueil en santé mentale de personnes en processus de transsexualisation ayant pour base une recherche qualitative et en utilisant la méthode de l'auto-ethnographie relationnelle. À partir des récits des sujets, nous discutons le processus d'arrivée à la réception, la transformation complexe du corps et de l'identité de genre, ainsi que la fonction de la réception pendant ce processus. Nous soulignons la pratique narrative et le partage d'histoires personnelles comme moyen de produire de nouvelles significations pour l'expérience unique de la transition entre les sexes, en tirant parti des différences comme moyen de chercher une vision plus ample et la possibilité de coexistence de perspectives multiples. Enfin, nous soulignons l'approche psychosociale comme stratégie fondamentale pour la construction de soins partagés, complets et horizontaux qui favorisent l'autonomie des usagers et satisfont leurs besoins.

Mots clés: Processus de transsexualisation, santé mentale, récits, accueil

(Una transición compartida: sobre el acogimiento en salud mental en una consulta externa para el proceso de transexualización dentro del sistema público de salud brasileño)

Este artículo aborda el acogimiento en salud mental de personas que se encuentran en el proceso de transexualización a través de una investigación cualitativa y hace uso del método de autoetnografía relacional. Discutimos, a partir de las narrativas de los participantes, el proceso de llegada al servicio de 


\section{ARTIGOS}

acogimiento, la compleja transformación del cuerpo y de la identidad de género, y la función del acogimiento en esta jornada. Destacamos la práctica narrativa y el intercambio de historias personales como una forma de producir nuevos significados para la experiencia única de la transición de género, aprovechando las diferencias para buscar una visión más amplia y la posibilidad de coexistencia de múltiples perspectivas. Finalmente, destacamos el enfoque psicosocial como estrategia fundamental para construir una atención compartida, integral, horizontal, que favorezca la autonomía de los usuarios y que satisfaga sus necesidades.

Palabras clave: Proceso de transexualización, salud mental, narrativas, acogimiento

Citação/Citation: Cabral, C. C., \& Muñoz, N. M. (2021, junho). Uma transição compartilhada: sobre o acolhimento em saúde mental em um ambulatório do processo transexualizador do SUS. Revista Latinoamericana de Psicopatologia Fundamental, 24(2), 259-280. http:// dx.doi.org/10.1590/1415-4714.2021v24n2p259.3.

Editora/Editor: Profa. Dra. Ana Maria G. R. Oda

Submetido/Submitted: 19.8.2020 / 8.19.2020 Aceito/Acepted: $21.12 .2020 / 12.21 .2020$

Copyright: (C) 2009 Associação Universitária de Pesquisa em Psicopatologia Fundamental/ University Association for Research in Fundamental Psychopathology. Este é um artigo de livre acesso, que permite uso irrestrito, distribuição e reprodução em qualquer meio, desde que o autor e a fonte sejam citados / This is an open-access article, which permits unrestricted use, distribution, and reproduction in any medium, provided the original authors and sources are credited. 
Financiamento/Funding: Este trabalho não recebeu apoio / This work received no funding. Conflito de interesses/Conflict of interest: As autoras declaram que não há conflito de interesses. / The authors declare that there is no conflict of interes

Clarice Cezar Cabral

Mestre em Atenção Psicossocial pelo Instituto de Psiquiatria da Universidade Federal do Rio de Janeiro - UFRJ (Rio de Janeiro, RJ, Br.); Psicóloga do Instituto de Psiquiatria da Universidade Federal do Rio de Janeiro - UFRJ (Rio de Janeiro, RJ, Br.)

Rua General Glicério, 95/102 - Laranjeiras

22245-120 Rio de Janeiro, RJ, Br.

clarice.cabral@ipub.ufrj.br

https://orcid.org/0000-0002-3846-1473

Nuria Malajovich MuÑoz

Professora associada do Instituto de Psiquiatria da Universidade Federal do Rio de Janeiro - UFRJ (Rio de Janeiro, RJ, Br).

Rua General Glicério 326/603 - Laranjeiras

22245-120 Rio de Janeiro, RJ, Br.

nuriamalajovich@gmail.com

https://orcid.org/0000-0003-3872-818X

This is an open-access article, which permits unrestricted use, distribution, the original authors and sources are credited. 